\title{
The Relationship Between Oxidative Damage and Vitamin E Concentration in Blood, Milk, and Liver Tissue from Vitamin E Supplemented and Nonsupplemented Periparturient Heifers
}

\author{
R. J. Bouwstra, ${ }^{* 1}$ R. M. A. Goselink, ${ }^{*}$ P. Dobbelaar, ${ }^{*}$ M. Nielen, ${ }^{*}$ J. R. Newbold, $\dagger$ and T. van Werven \\ ${ }^{*}$ Faculty Veterinary Medicine, Department of Farm Animal Health, Utrecht University, Utrecht, the Netherlands \\ †Provimi Research and Innovation Centre, Brussels, Belgium
}

\section{ABSTRACT}

This study investigated the relationship between oxidative damage and the effect of vitamin $\mathrm{E}$ supplementation in blood, milk, and liver tissue in 16 periparturient heifers. The question is whether measurements of oxidative and vitamin $\mathrm{E}$ status in blood of a periparturient cow are representative of the total body, given that blood concentrations of both vitamin $\mathrm{E}$ and oxidative stress products change around this period. The daily vitamin $\mathrm{E}$ intake of the vitamin E-supplemented Holstein-Friesian heifers $(\mathrm{n}=8)$ was 3,000 international units and was started 2 mo before calving; the control heifers $(\mathrm{n}=8)$ were not supplemented. Oxidative damage was determined on the basis of malondialdehyde (MDA) concentrations. Blood was sampled 9 times before calving, on calving day, and twice after calving. Liver biopsies were taken at wk $-5,-1$, and 2 relative to calving day. Milk was obtained from all heifers immediately after calving, the first 2 milkings and on $\mathrm{d} 3,7$, and 14 at $0600 \mathrm{~h}$. Serum and liver tissue were analyzed for vitamin E, cholesterol, and MDA; and milk samples were analyzed for vitamin E, MDA, fat, protein, and somatic cell count. The results showed that vitamin $\mathrm{E}$ supplements increased both absolute vitamin E concentrations and the ratio of vitamin $\mathrm{E}$ to cholesterol in blood and liver tissue. Absolute vitamin $\mathrm{E}$ concentration in milk tended to be greater in supplemented cows. Based on the increased MDA blood concentrations at calving, it seems that dairy heifers experience oxidative stress. The effect of vitamin E on MDA differs between the blood, liver, and mammary gland. Vitamin E supplementation could not prevent the increase in blood MDA at calving, but the significantly lower MDA blood concentrations of supplemented cows in the 2 wk after calving suggest that vitamin $\mathrm{E}$ has a role in recovery from parturition-related oxidative stress. Vitamin E

Received August 9, 2007.

Accepted November 25, 2007.

${ }^{1}$ Corresponding author: R.J.Bouwstra@vet.uu.nl supplementation reduced oxidative damage in liver, whereas no obvious effect was found on milk MDA concentrations. A strong relationship was found between blood and liver vitamin $\mathrm{E}$ and the ratio of vitamin $\mathrm{E}$ to cholesterol. Concentrations of MDA in blood and milk were also strongly related. The results show that the relationship between oxidative damage and vitamin $\mathrm{E}$ differs within blood, liver tissue, and milk. This implies that oxidative and vitamin $\mathrm{E}$ status calculated on the basis of blood values alone should be interpreted with caution and cannot be extrapolated to the whole animal. Key words: oxidative damage, vitamin E, dairy heifer

\section{INTRODUCTION}

During the transition period (late gestation and early lactation) dairy cows experience drastic physiological changes critical for their health and subsequent performance. Supplementation of vitamin E during this period is associated with their enhanced health (Weiss et al., 1990a), and oxidative stress during this transition can contribute to diseases and disorders (Miller et al., 1993). Oxidative stress occurs when the balance between antioxidants and free oxygen radicals is disturbed and leads to damage of biological macromolecules and disruption of cell structures (Trevisan et al., 2001). Vitamin E, as a powerful antioxidant, lowers oxidative stress and influences the health of dairy cows (Burton and Traber, 1990). Vitamin E is absorbed and transported from the intestine to the liver following the same mechanisms as lipids. In the liver, $\alpha$-tocopherol is packaged in lipoproteins and distributed from the liver via plasma to the rest of the body (Herdt and Smith, 1996).

Particularly in the transition period, blood concentrations of both vitamin $\mathrm{E}$ and certain oxidative stress products change. For example, the plasma concentration of $\alpha$-tocopherol decreases during the last month prepartum (Goff and Stabel, 1990; Weiss et al., 1990a; LeBlanc et al., 2002) and oxidative stress increases around parturition (Bernabucci et al., 2002; Castillo et al., 2005). The reason for lower $\alpha$-tocopherol concentra- 
tions in blood in the last few weeks before parturition and their relationship with oxidative stress is not quite clear. The decrease of vitamin $\mathrm{E}$ blood concentration may be due in part to the distribution of vitamin $\mathrm{E}$ to other parts of the body such as the mammary gland (Weiss et al., 1990b), but could also be caused by a change in fat metabolism (Herdt and Smith, 1996), in which the liver plays an important role. The metabolic activity increases during the transition period, especially in the liver and mammary gland. This switch to a higher metabolic activity is accompanied by higher oxygen radical production (Lohrke et al., 2005), which may cause greater concentrations of oxidative damage products if antioxidant status is inadequate.

Previously, researchers used blood to assess vitamin $\mathrm{E}$ and oxidative status of transition dairy cows (Brzezinska-Slebodzinska et al., 1994; Bernabucci et al., 2002). However, blood concentrations of vitamin $\mathrm{E}$ and oxidative stress products may not be representative of those in other organs, especially during the transition period. Therefore, it could be important to measure vitamin $\mathrm{E}$ and indicators of oxidative stress in individual organs and tissues, such as the liver and mammary gland, as well as in blood. Toxicological research in rats emphasizes that oxidative damage at the organ level is influenced by vitamin $\mathrm{E}$ administration (Naziroglu et al., 2004). Given its importance as an antioxidant, one could expect that the concentration of vitamin $\mathrm{E}$ in tissues undergoing great change would influence the local degree of oxidative stress. However, to our knowledge, there are no reports on oxidative damage products in liver and mammary gland, nor studies of correlations between the concentrations in these organs and blood.

The aim of this study was to investigate the relationship between oxidative damage measured in blood, milk, and liver tissue and the effect of vitamin E supplementation on oxidative damage in periparturient Holstein-Friesian heifers.

Concentrations of malondialdehyde (MDA), a degradation product of lipid peroxidation (Halliwell and Chirico, 1993), were used as a proxy measure for oxidative damage. Malondialdehyde is formed under oxidative stress conditions (Nielsen et al., 1997) and offers the advantage that it can be measured in blood as well as in liver tissue and in milk.

\section{MATERIALS AND METHODS}

The experiment was conducted at the Faculty of Veterinary Medicine, Utrecht University, the Netherlands. The Committee for Animal Experiments of Utrecht University approved the experimental protocol.

\section{Animals}

The experiment, carried out from March to June 2006, used 18 pregnant Holstein heifers. The heifers were divided into 2 experimental groups, matched for BCS. All heifers calved in May. Heifers were housed in a tie-stall barn during the experiment and were fed with grass silage, corn silage, mineral supplement, and concentrates to meet Dutch standards for energy and protein from the Central Bureau for Livestock Feeding (CVB). Prepartum the basal diet consisted of $1.7 \mathrm{~kg}$ (DM) of corn silage and ad libitum grass silage followed postpartum by $2.6 \mathrm{~kg} \mathrm{DM}$ of corn silage and ad libitum grass silage. All silages were analyzed for energy content. Concentrates were added to the diet after calving with a gradual increase from 2 to $7 \mathrm{~kg}$ at d 18 after calving. The concentrate was a compound feed with a fat concentration of $40 \mathrm{~g} / \mathrm{kg}$. The maximum energy value of the diet during lactation was estimated at $26.5 \mathrm{Mcal}$ of $\mathrm{NE}_{\mathrm{L}} / \mathrm{d}$ (15.7 from silages and 10.8 from concentrates). Vitamin E concentration was measured once in the grass silage fed prepartum and once in the grass silage fed postpartum, at 9.3 and $23 \mathrm{mg}$ of $\alpha$-tocopherol $/ \mathrm{kg}$ of DM, respectively.

Vitamin E (3,000 IU/d) was supplied in a corn-based carrier $(100 \mathrm{~g} / \mathrm{d})$ mixed through the corn silage every afternoon. The vitamin E supplementation was provided at a high 3,000 IU per animal per day to try to prevent the expected decrease in vitamin $\mathrm{E}$ blood concentration just before calving. Earlier research with $1,000 \mathrm{IU} / \mathrm{d}$ still resulted in a prepartum decrease (Weiss et al., 1990b; Brzezinska-Slebodzinska et al., 1994). Others suggested that a prepartum supplementation of 3,000 IU/d had a positive effect on bovine neutrophil function and milk quality (Politis et al., 2004). The control group received an equal portion of this carrier (100 g/d) without vitamin E, also mixed through the corn silage every afternoon. Supplementation started $8 \mathrm{wk}$ before predicted calving date and lasted until 2 wk after calving. We defined the supplementation period as the transition period.

Two of 18 experimental animals were excluded from the results. One was delivered by caesarean section; both experienced abomasal displacement, which was surgically repositioned. Their corn silage and supplement intake was continuously low.

A third cow also experienced abomasal displacement, which was diagnosed at an early stage and repositioned surgically. This cow had good supplement intake and remained in the experiment. Results are therefore based on 16 animals: the control group and the vitamin E group both comprising 8 cows. 


\section{Sampling Procedures}

Blood Sampling. During the experiment, heifers were sampled weekly except for the 2 wk before expected calving date, when they were sampled twice weekly. Samples were collected with BD Vacutainer systems and SST II Advance tubes (Becton Dickinson, Plymouth, UK) at $0800 \mathrm{~h}$ and kept at 6 to $10^{\circ} \mathrm{C}$ before they arrived at the laboratory. Blood samples were centrifuged for $15 \mathrm{~min}$ at $4,465 \mathrm{rpm}(3,500 \times g)$ and $4^{\circ} \mathrm{C}$. Sera were frozen at $-80^{\circ} \mathrm{C}$ until analysis. Serum was analyzed for vitamin $\mathrm{E}$, cholesterol, and MDA.

Liver Biopsies. Liver biopsies were taken at wk -5 and -1 relative to expected calving day and wk 2 of lactation. Blood samples and milk samples (after calving) were obtained simultaneously for correlation analysis. The biopsy areas $\left(80 \mathrm{~cm}^{2}\right)$ between the 11th and 12th costae and at the level of the greater trochanter were clipped, scrubbed with an antiseptic solution, and disinfected. A local anesthetic was given subcutaneously $(7 \mathrm{~mL}$ of lidocaine- $\mathrm{HCl} 2 \%$ with adrenaline, Alfasan Nederland b.v., Woerden, the Netherlands) before a stab incision was made. Approximately $400 \mathrm{mg}$ of liver tissue (wet weight) was collected with a $17 \mathrm{G} \times$ $200-\mathrm{mm}$ biopsy needle. The liver tissue was immediately frozen in liquid nitrogen $\left(-196^{\circ} \mathrm{C}\right)$. After thawing, PBS was added to biopsy material (5:1) and the sample homogenized. Homogenized samples were then centrifuged at $15,800 \times g$ and refrozen at $-80^{\circ} \mathrm{C}$ until analysis. Samples were analyzed for vitamin E, cholesterol, MDA, and total protein content. Liver concentrations were corrected for differences due to the homogenization process by calculating all concentrations per milligram of protein.

Milk Sampling. Milk was obtained from all heifers immediately after calving, the first 2 milkings after calving and at d 3, 7, and 14 at $0600 \mathrm{~h}$. A blood sample was collected simultaneously directly after calving and on $\mathrm{d} 7$ and 14 for correlation with milk analysis. Milk samples were stored at $-80^{\circ} \mathrm{C}$ until analyzed for vitamin $\mathrm{E}$ and MDA, fat, protein, and SCC.

\section{Laboratory Analysis}

Vitamin E ( $\alpha$-tocopherol) was measured with HPLC with both ultraviolet and fluorescence detection using a kit from Chromsystems (Munich, Germany). Cholesterol and total protein concentrations were determined routinely on a clinical autoanalyzer (Hitachi 912, Roche Diagnostics, Almere, the Netherlands) using kits from Roche Diagnostics. Malondialdehyde was measured by using an isocratic Varian HPLC system from Chromsystems. A 10-cm C18 cartridge was used (Varian) with a flow rate of $1.0 \mathrm{~mL} / \mathrm{min}$ at ambient temperature $\left(25^{\circ} \mathrm{C}\right)$. Fluorescence detection (Jasco Separations, HI
Ambacht, the Netherlands) occurred with excitation at $515 \mathrm{~nm}$ and emission at $553 \mathrm{~nm}$. All analyses were done at The National Institute for Public Health and the Environment (RIVM, Bilthoven, the Netherlands).

Fat and protein concentrations in milk were determined with mid infrared spectrometry (MilkoScan 4000 or MilkoScan FT6000, Foss, Hillerød, Denmark) according to an IDF standard method method 141C; IDF, 2000). The SCC was determined by flow cytometry according to an ISO/IDF method (method 13366-2 1482; ISO/IDF, 2006). These analyses were done at Milk Control Station (Zutphen, the Netherlands).

\section{Statistical Analysis}

To find trends in time and differences between treatments, vitamin $\mathrm{E}$ and oxidative damage in blood, liver tissue, and milk were studied in mixed models, with group and group $\times$ time interaction as fixed effects and cow as random effect. Blood samples were divided into 6 time intervals related to calving date. Time interval 1 was the start of supplementation, time interval 2 was 2 wk later, time interval 4 was defined as the mean concentration of wk $-2,-1.5,-1$, and -0.5 , time interval 5 was at calving, and time interval 6 was defined as the mean concentration of wk 1 and 2 after parturition. Group $\times$ time interaction in blood was tested against the base line (time interval 3), defined as the mean concentration of wk $-5,-4$, and -3 . Group $\times$ time interaction in liver and milk was tested against the final measurement at d 14 after parturition.

To investigate the relationship between MDA and vitamin $\mathrm{E}$ in blood, liver, and milk, partial correlation coefficients were calculated between MDA and vitamin $\mathrm{E}$ at compartment level, corrected for group and repeated measures. Data were $\log _{10}$ transformed to create normally distributed concentrations.

Mixed model analysis with cow as random effect and group as fixed effect was used to evaluate the relationship between concentrations in the 3 compartments: blood, milk, and liver. In these regression models, vitamin $\mathrm{E}$ and MDA concentrations in liver tissue and milk were used as predictors, with blood concentrations as dependent variable. To correct for lipid concentrations in blood, liver, and milk, ratios of vitamin $\mathrm{E}$ were calculated using cholesterol concentrations in blood and liver tissue and fat percentage of milk. For all analyses, significance was set at $P \leq 0.05$, and all analyses were carried out in SPSS 12.0.1 for Windows (SPSS Inc., Chicago, IL).

\section{RESULTS}

\section{Group and Group $\times$ Time Interaction}

The results of differences between treatments and time trends are summarized in Table 1 and Figures 1, 
Table 1. Results ( $P$-values) of linear mixed models with cow as random effect, group and group $\times$ time interaction as fixed effects for the dependent variables vitamin E, cholesterol, the ratio vitamin E:cholesterol, and malondialdehyde in blood and liver tissue and for the dependent variables vitamin $\mathrm{E}$, fat percentage, the ratio vitamin $\mathrm{E}$ :fat percentage, malondialdehyde, and SCC in milk

\begin{tabular}{lcc}
\hline & Time & \\
Item & $\times$ group & Group \\
\hline Blood & & \\
Vitamin E ( $\mu \mathrm{mol} / \mathrm{L})$ & 0.001 & 0.002 \\
Cholesterol $(\mathrm{mmol} / \mathrm{L})$ & 0.001 & 0.202 \\
Ratio of vitamin E:cholesterol (mmol/L) & 0.001 & 0.001 \\
Malondialdehyde ( $\mu \mathrm{g} / \mathrm{L})$ & 0.001 & 0.542 \\
Liver tissue & & \\
Vitamin E (nmol/gram protein) & 0.780 & 0.001 \\
Cholesterol (mmol/gram protein) & 0.111 & 0.418 \\
Ratio of vitamin E:cholesterol (mmol/gram protein) & 0.319 & 0.020 \\
Malondialdehyde ( $\mu \mathrm{g} /$ gram protein) & 0.026 & 0.869 \\
Milk & & \\
Vitamin E ( $\mu \mathrm{mol} / \mathrm{L})$ & 0.146 & 0.117 \\
Fat percentage $(\%)$ & 0.221 & 0.756 \\
Ratio of vitamin E:fat\% ( $\mu$ mol/\%) & 0.234 & 0.459 \\
Malondialdehyde $(\mu \mathrm{g} / \mathrm{L})$ & 0.000 & 0.570 \\
SCC & 0.029 & 0.228 \\
\hline
\end{tabular}

2, and 3. The vitamin E concentration and the vitamin E:cholesterol ratio in blood were greater in the supplemented group $(P<0.01)$. In the control group vitamin E concentrations start to decrease in the 2 wk before parturition $(P=0.029)$. In both groups, vitamin $\mathrm{E}$ concentrations decreased at calving (control group, $P=$ 0.044; vitamin E group, $P=0.036$ ) and increased after calving (control group, $P=0.007$; vitamin E group, $P=$ 0.016). The vitamin E:cholesterol ratio increased 2 wk before calving in the supplemented group $(P=0.024)$ and remained steady after parturition, whereas in the same period, this ratio decreased in the nonsupplemented group and increased $(P<0.01)$ after parturition. In both groups, MDA concentrations increased (control group, $P=0.039$; vitamin $\mathrm{E}$ group, $P<0.01$ ) at calving, but only in the supplemented group did they decrease after parturition $(P<0.01)$.

Vitamin $\mathrm{E}$ concentration and the ratio of vitamin $\mathrm{E}$ to cholesterol in liver tissue were greater in the supplemented group $(P<0.01$ and $P=0.02$, respectively). Concentrations of MDA decreased in the supplemented group $(P=0.003)$ and tended to increase in the control group.

Vitamin E concentrations in milk tended to be greater in the supplemented group. Concentrations of MDA in both groups were high in the first 3 milkings $(P<0.01)$ and decreased in the following period. Somatic cell count in the control group was high in the first 3 milkings and decreased thereafter. In the supplemented group, fewer SCC fluctuations were observed and SCC tended to be lower.

\section{Correlations of Vitamin E, Ratios, and MDA Within Blood, Liver, and Milk}

The results of correlations within blood, liver, and milk are summarized in Table 2 . For blood, vitamin E was strongly correlated to cholesterol $(\mathrm{r}=0.725, P<$ 0.01 ), which means greater cholesterol often coexisted with greater vitamin $\mathrm{E}$ concentrations. In the liver, MDA was weakly and positively correlated with cholesterol ( $\mathrm{r}=0.327, P=0.028)$, and weakly and negatively correlated with the ratio of vitamin E:cholesterol ( $\mathrm{r}=$ $-0.392, P=0.008)$. Greater concentrations of vitamin E tended to coexist with lower concentrations of MDA ( $\mathrm{r}=-0.286, P=0.057)$. In milk, MDA correlated weakly and positively with the ratio vitamin E:fat percentage ( $\mathrm{r}=0.223, P=0.038)$.

\section{Relationship Between Vitamin E, Ratios, and MDA in Blood, Liver, and Milk}

The dependent blood variables vitamin $\mathrm{E}$, the ratio of vitamin E:cholesterol, and MDA were modeled in linear mixed models with cow as random effect (Table 3). Vitamin E blood concentration is related to vitamin E concentrations in liver $(P=0.003)$ and milk $(P=$ 0.003). The ratio of vitamin E:cholesterol in blood is related to the ratio of vitamin E:cholesterol in liver tissue $(P=0.007)$. The concentration of MDA in blood is related to the MDA concentration in milk $(P=0.030)$.

\section{DISCUSSION}

In studying the relationship between blood, milk, and liver tissue oxidative damage and the effect of vitamin E supplementation in Holstein-Friesian heifers, we focused on the periparturient period because of the presence of oxidative stress (Castillo et al., 2005) and its possible relation with health problems in following lactation (Miller et al., 1993). Heifers were used because they show functional changes in oxidative reactions compared with multiparous cows (Mehrzad et al., 2002). Moreover, heifers at the beginning of lactation have not yet been exposed to stressors related to a previous lactation, such as milking, metabolic diseases, and mastitis, which could bias the results.

\section{Vitamin E}

Blood. Vitamin E supplementation resulted in increases in vitamin $\mathrm{E}$ blood concentrations and in the ratio of vitamin E:cholesterol. This is in agreement with other research (Goff and Stabel, 1990; Weiss et al., 1990b). After 2 wk of supplementation, the values of vitamin $\mathrm{E}$ in the supplemented group were statistically similar across sampling times before calving, sug- 


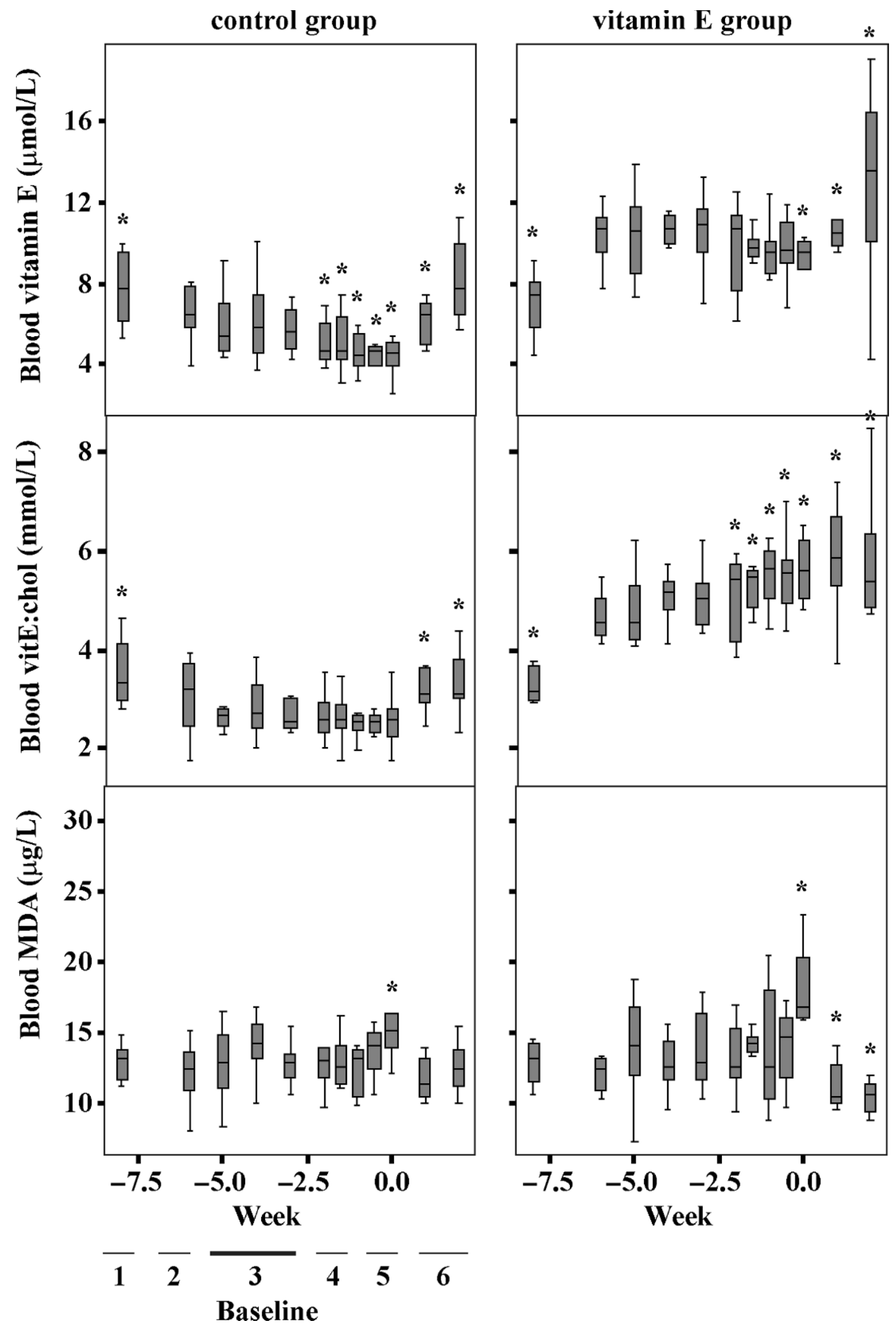

Figure 1. Blood vitamin E, the ratio vitamin E:cholesterol (vitE:chol), and malondialdehyde (MDA) in control and vitamin E group during experimental period. Displayed are medians and quartiles. * Significant group $\times$ time interaction compared with the baseline $(P<0.05)$. 

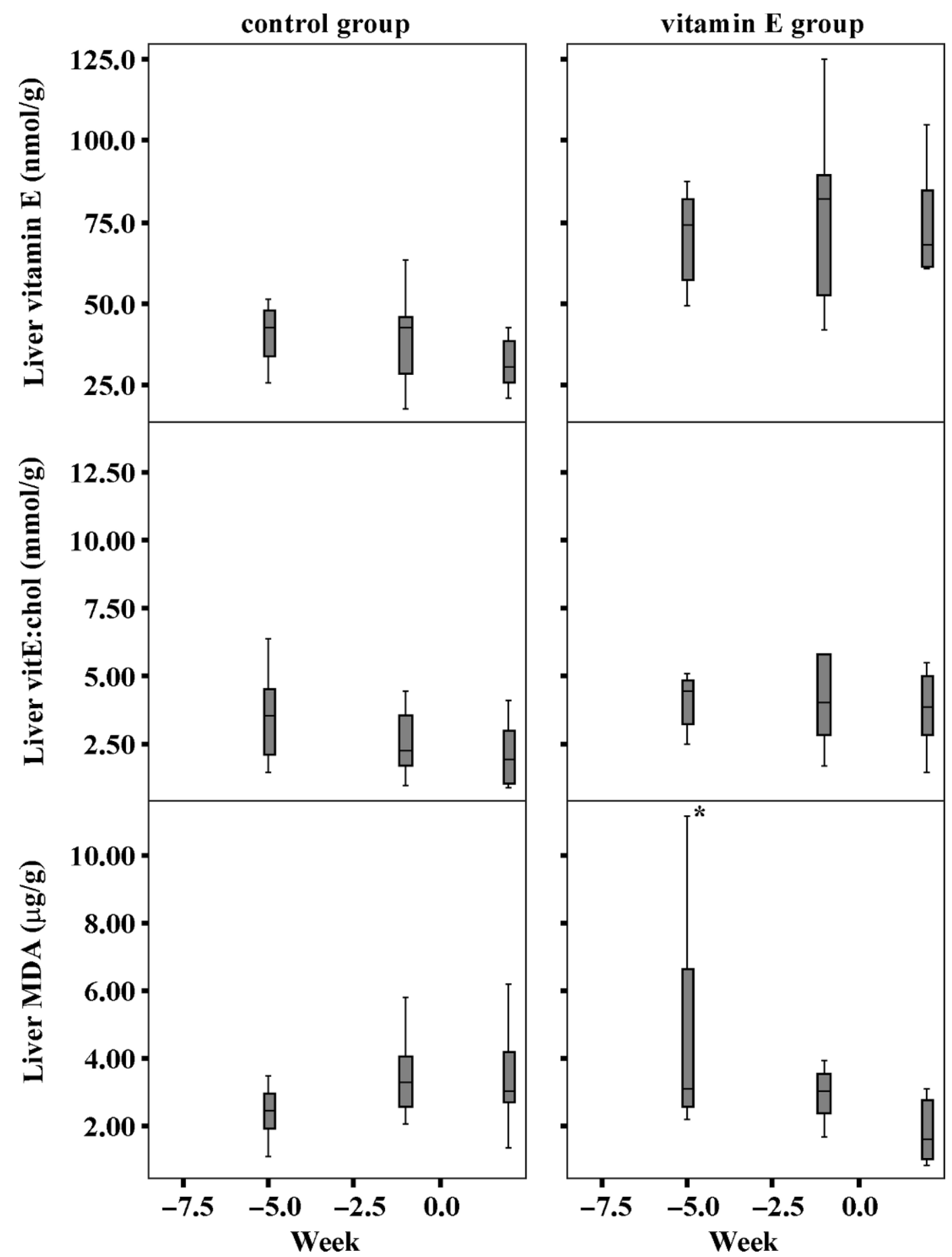

Figure 2. Liver vitamin E, the ratio vitamin E:cholesterol (vitE:chol), and malondialdehyde (MDA) in control and vitamin E group during experimental period. Displayed are medians and quartiles. *Significant group $\times$ time interaction compared with the final measurement at d 14 after parturition $(P<0.05)$.

gesting that a steady vitamin $\mathrm{E}$ state was reached. Supplementation of 3,000 IU/d was almost high enough to prevent a decrease in blood vitamin $\mathrm{E}$ concentration prepartum; other research, using supplementation at
$1,000 \mathrm{IU} / \mathrm{d}$, found lower concentrations in prepartum supplemented cows (Brzezinska-Slebodzinska et al., 1994; Smith et al., 1997). Cholesterol is a component of very low density lipoproteins (VLDL), along with 

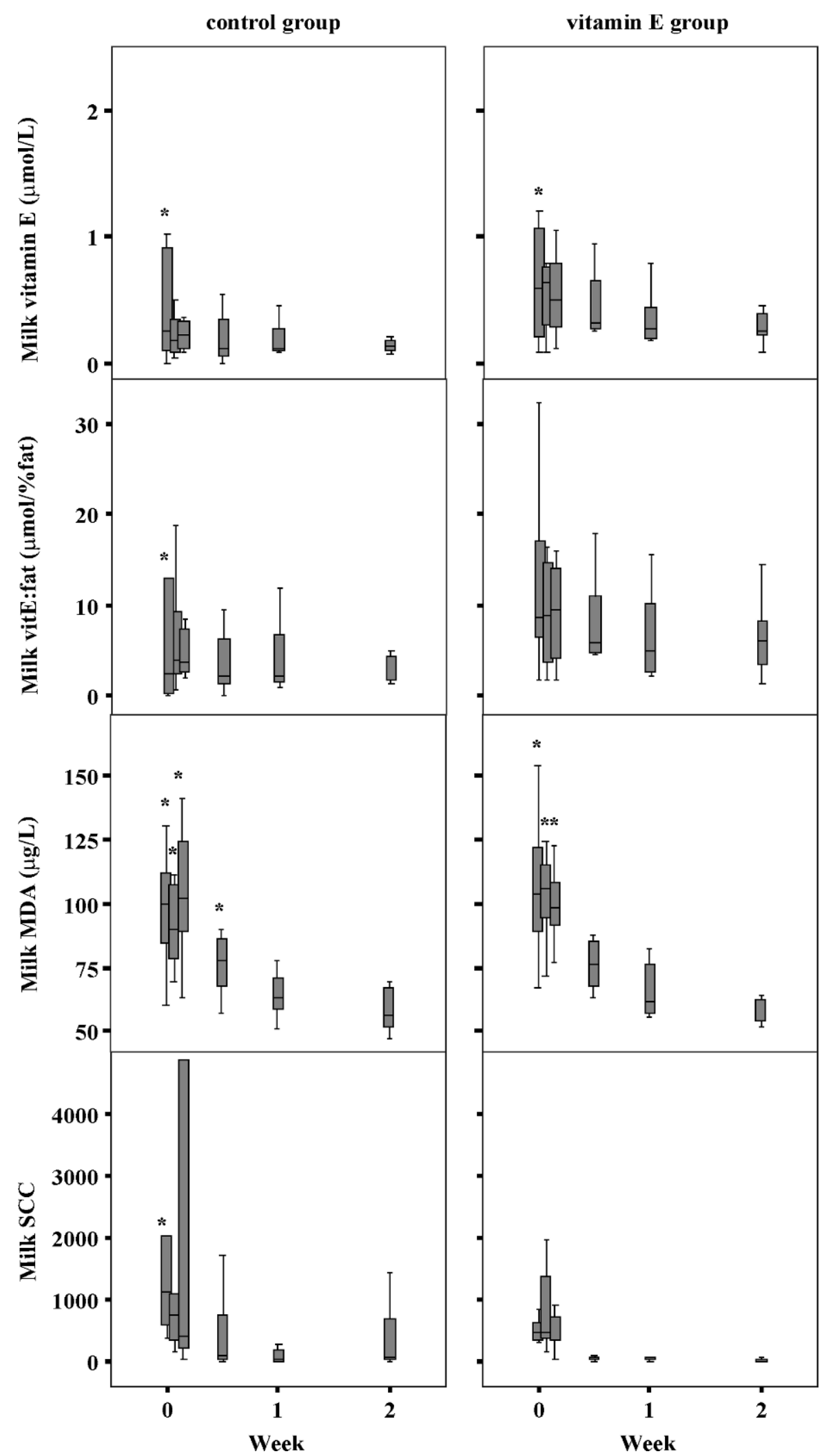

Figure 3. Milk vitamin E, the ratio vitamin E:fat percentage (vitE:fat), malondialdehyde (MDA), and SCC in control and vitamin E group during experimental period. Displayed are medians and quartiles *Significant group $\times$ time interaction compared with the final measurement at d 14 after parturition $(P<0.05)$. 
Table 2. Results of partial correlation corrected for group and repeated measures ${ }^{1}$

\begin{tabular}{|c|c|c|c|c|}
\hline & Vitamin $\mathrm{E}$ & Cholesterol & MDA & \\
\hline \multicolumn{5}{|l|}{ Blood } \\
\hline Vitamin E $(\mu \mathrm{mol} / \mathrm{L})$ & - & & & \\
\hline Cholesterol (mmol/L) & $0.725^{* * *}$ & - & & \\
\hline Malondialdehyde ( $\mu \mathrm{g} / \mathrm{L})$ & -0.033 & -0.048 & - & \\
\hline Ratio vit E:chol ${ }^{2}(\mathrm{mmol} / \mathrm{L})$ & - & - & -0.004 & \\
\hline \multicolumn{5}{|l|}{ Liver tissue } \\
\hline Vitamin E (nmol/gram protein) & - & & & \\
\hline Cholesterol (mmol/gram protein) & -0.214 & - & & \\
\hline Malondialdehyde ( $\mu \mathrm{g} / \mathrm{gram}$ protein) & $-0.286 \dagger$ & $0.327 *$ & - & \\
\hline Ratio vit E:chol (mmol/gram protein) & - & - & $-0.392^{* *}$ & \\
\hline Milk & Vitamin E & Fat $\%$ & MDA & Ratio vit E:fat $\%$ \\
\hline Vitamin $E(\mu \mathrm{mol} / \mathrm{L})$ & - & & & \\
\hline Fat percentage $(\%)$ & -0.197 & - & & \\
\hline Malondialdehyde ( $\mu \mathrm{g} / \mathrm{L})$ & 0.176 & -0.085 & - & \\
\hline Ratio vit E:fat $\%^{3}(\mu \mathrm{mol} / \%)$ & - & - & $0.223^{*}$ & - \\
\hline $\mathrm{SCC}$ & 0.003 & $0.313^{* *}$ & -0.036 & -0.102 \\
\hline
\end{tabular}

triacylglycerol, cholesterol esters, phospholipids, and various apolipoproteins. As a lipophilic molecule, vitamin $\mathrm{E}$ is expected to "hitch a ride" in the VLDL. Cholesterol can more easily be measured than VLDL. The high positive correlation between vitamin $\mathrm{E}$ and cholesterol was expected and confirms that increased lipoprotein in blood will influence the blood concentration of vitamin $\mathrm{E}$. The ratio of vitamin E:cholesterol is therefore calculated to correct for transport capacity in blood (Herdt and Smith, 1996). Cholesterol increased after parturition in both groups. No group differences were found for cholesterol, so the higher ratio in the supplemented group also indicated a greater vitamin E concentration per lipoprotein particle.

Liver. Vitamin E supplementation in our study resulted in greater vitamin $\mathrm{E}$ concentrations in liver tis- sue, which has also been reported in cattle, mice, and rats (Nockels et al., 1996; Ferre et al., 2001). The ratio of vitamin E:cholesterol is a commonly used as a blood value. In liver tissue, the ratio was also greater in the supplemented group, and the results show less individual variation compared with absolute vitamin E concentrations in liver tissue. No reports are available on the usefulness of this ratio in liver tissue.

Milk. Absolute vitamin $\mathrm{E}$ concentration in milk tended to be greater in supplemented cows. It has been reported that supplementation of vitamin $\mathrm{E}$ will increase its secretion in colostrum when the amount is expressed on a fat basis (Weiss et al., 1990b) and also that the concentration per milliliter of milk will increase (Baldi et al., 2000). The exact process involved in the final transportation of tocopherols into milk fat

Table 3. Results of linear mixed models analysis with cow as random effect ${ }^{1}$

\begin{tabular}{|c|c|c|c|c|}
\hline Item & Estimate & SE & $\begin{array}{l}95 \% \text { Confidence } \\
\text { interval }\end{array}$ & $P$-value \\
\hline \multicolumn{5}{|l|}{ Dependent blood vitamin $\mathrm{E}(\mu \mathrm{mol} / \mathrm{L})$} \\
\hline Predictor milk vitamin $\mathrm{E}(\mu \mathrm{mol} / \mathrm{L})$ & 0.30 & 0.082 & $0.12-0.47$ & 0.003 \\
\hline Predictor liver tissue vitamin E (nmol/gram protein) & 0.47 & 0.13 & $0.19-0.75$ & 0.003 \\
\hline \multicolumn{5}{|l|}{ Dependent blood ratio vitE: $\mathrm{chol}^{2}(\mathrm{mmol} / \mathrm{L})$} \\
\hline Predictor milk ratio vitE:fat $\%^{3}(\mu \mathrm{mol} / \%)$ & 0.13 & 0.065 & $0.008-0.28$ & 0.062 \\
\hline Predictor liver tissue ratio vit E:chol (mmol/gram protein) & 0.33 & 0.10 & $0.107-0.55$ & 0.007 \\
\hline \multicolumn{5}{|l|}{ Dependent blood $\mathrm{MDA}^{4}(\mu \mathrm{g} / \mathrm{L})$} \\
\hline Predictor milk MDA $(\mu \mathrm{g} / \mathrm{L})$ & 2.44 & 1.00 & $0.27-4.61$ & 0.030 \\
\hline Predictor liver tissue MDA ( $\mu \mathrm{g} / \mathrm{gram}$ protein) & 0.11 & 0.14 & $-0.18-0.41$ & 0.423 \\
\hline
\end{tabular}

${ }^{1}$ Blood variables were used as dependent and milk and liver parameters as predictors.

${ }^{2}$ Ratio of vitamin E:cholesterol.

${ }^{3}$ Ratio of vitamin E:fat percentage.

${ }^{4} \mathrm{MDA}=$ malondialdehyde. 
is not known. It may be that daily $\alpha$-tocopherol secretion in milk is limited in quantity and is independent of the yields of milk and milk fat (Jensen et al., 1999). Our results confirm these findings, because no correlations were found between fat percentages and vitamin $\mathrm{E}$ concentrations in milk.

\section{MDA}

Different definitions of oxidative stress are used in the literature. For example, Bernabucci et al. (2005) defined oxidative stress as a result of an imbalance between production of reactive oxygen metabolites and the neutralizing capacity of antioxidant mechanisms; Castillo et al. (2005) defined oxidative stress as free radical generation exceeding the body's antioxidant production capacity. We defined oxidative stress as a low ratio of antioxidant to free radicals; free radicals can cause lipid peroxidation. Malondialdehyde is one of the lipid peroxidation products and is thus often used as indicator of oxidative damage (Nielsen et al., 1997). In previous studies, increased blood concentrations of MDA or precursors of MDA (thiobarbituric acid-reactive substances) have also been found in periparturient cows (Bernabucci et al., 2005; Castillo et al., 2005). Increased tissue concentrations of MDA have been found in rats measured under oxidative stress conditions (Koksal et al., 2004), and vitamin E supplementation has decreased the concentration of MDA in the liver of rats (Naziroglu et al., 2004). Total oxidative status cannot be based on MDA concentrations alone (Halliwell and Chirico, 1993), but measurements on oxidative damage have been used as indicators of oxidative stress before (Nielsen et al., 1997). The measurement of MDA by HPLC, as measured in this study, is a sensitive and, importantly, a specific method for determining the MDA molecule itself and not other related aldehyde compounds. Malondialdehyde is, together with hydroxynonenal, one of the main intermediates between of lipid peroxidation and oxidative stress. The main source is the pool of polyunsaturated fatty acids, but not oleic acid because it is not prone to oxidation, or prostaglandin $\mathrm{H}_{2}$, which is, quantitatively, a minor pathway compared with others. There is evidence that MDA can result from oxidative stress in human studies. Increased MDA levels were reported in relation to the postprandial phenomenon of oxidative stress (van Oostrom et al., 2003) and the glucose-induced oxidative stress.

Blood. The data of this study confirmed that, based on MDA blood concentrations, periparturient heifers experience oxidative stress, and that the effect of vitamin $\mathrm{E}$ on MDA differs between the blood, liver, and the mammary gland. Vitamin E supplementation could not prevent the increase in blood MDA at calving, but the lower MDA blood concentrations of supplemented cows in the $2 \mathrm{wk}$ after calving suggest a role of vitamin $\mathrm{E}$ in recovering from parturition-related oxidative stress.

Liver. Especially in periparturient cows, the liver performs essential functions in metabolism of glucose, lipid, triacylglycerol, and cholesterol. Various authors report a relationship between metabolic changes and oxidative stress (Bernabucci et al., 2005; O'Boyle et al., 2006) based on measurements in blood. Temporal gene expression profiling of liver from periparturient dairy cows reveals complex adaptive mechanisms in hepatic function. It is reported that the proinflammatory response is related to lipid mobilization and fatty acid oxidation (Loor et al., 2005). Given the important role of the liver in dealing with metabolic changes, oxidative damage and the influence of vitamin $\mathrm{E}$ at the liver level could be more important than concentrations measured in blood. Our data confirm this: vitamin E supplementation reduced oxidative damage in liver, whereas no obvious effects of supplementation were found in milk and blood MDA concentrations. The obvious difference between the effect of vitamin $\mathrm{E}$ on oxidative damage in blood, milk, and liver tissue indicates that the liver has a very important role in dealing with oxidative stress. To apply oxidative damage measurements in the field and to evaluate the effect of vitamin $\mathrm{E}$ supplementation on oxidative damage, these measurements need to be reliable. The concentration of MDA in blood may simply reflect the total oxidative damage formed in the rest of the body. Blood concentrations of MDA could be just a general measurement of mean body oxidative damage. Thus, the increase in blood MDA at calving may be unpreventable, because during parturition, high amounts of free radicals are formed. Indeed, in our study, vitamin E supplementation could not prevent the increase in MDA blood concentrations at calving.

However, the lower MDA blood concentrations of supplemented cows in the 2 wk after calving compared with those of control cows suggested that vitamin $\mathrm{E}$ has a role in recovering from oxidative stress. At the liver level, MDA decreased in the supplemented group, but tended to increase in the control group. The concentration of MDA in the liver was not correlated to absolute vitamin $\mathrm{E}$ concentrations, but was correlated to the ratio vitamin E:cholesterol. Studies of MDA concentrations in liver tissue of mice and rats confirm that vitamin E supplementation lowers MDA concentration in liver tissue (Ferre et al., 2001; Ohta et al., 2006). An increase in the ratio of vitamin E:cholesterol also implies a decrease in lipid peroxidation in liver tissue. This ratio may then be a better value for evaluating the antioxidant capacity of vitamin $\mathrm{E}$ in liver tissue. 
Milk. The importance of MDA in milk is even more difficult to evaluate. The question is whether it is formed or excreted in the mammary gland. The high concentrations at the beginning of lactation could support either theory. The MDA from blood might be excreted in the mammary gland and the high blood concentrations at calving may cause high concentrations of MDA in milk. But the change from nonlactating to lactating could also cause high levels of oxidative damage products in the mammary gland. We did not find that vitamin $\mathrm{E}$ had a positive effect on MDA concentrations in milk. This is explainable if milk MDA is a reflection of values in blood, because no effect of vitamin E on MDA was found in blood. In milk, the SCC group $\times$ time interaction was different, due to 2 cows with SCC $>1,000,000$ in the control group. Somatic cell count is an indicator of mastitis, and a low SCC generally represents good mammary health (Smith et al., 1997). Higher SCC in cows with low dietary vitamin E concentration compared with cows with high-dietary vitamin $\mathrm{E}$ has also been reported by various authors (Baldi et al., 2000; Moyo et al., 2004).

\section{Relationship Between Different Components}

In the mixed model analysis, blood was taken as a dependent variable. Blood is commonly used in research on vitamin $\mathrm{E}$ and oxidative damage, but it was actually not clear that milk concentrations could predict blood concentrations, nor whether blood is a good reflection of the liver. Thus, in our model, liver and milk are used as predictors and blood as a dependent variable.

Vitamin E. To evaluate vitamin E status, concentrations in blood, milk, and liver tissue are all useful as calculated in the mixed model. A strong relationship was found between blood and liver tissue concentrations. This relationship is not surprising, because we and others previously reported that vitamin $\mathrm{E}$ administration leads to greater blood and liver tissue concentrations (Hidiroglou et al., 1990; Arnold et al., 1993).

The Ratios. The ratio of vitamin E:cholesterol calculated in liver tissue is a useful predictor of the ratio in blood. It is well-known that the blood ratio is a more accurate value for vitamin $\mathrm{E}$ status of dairy cows (Herdt and Smith, 1996). In liver tissue, the ratio was also positively influenced by supplementation, and the results show less individual variation compared with absolute vitamin E concentrations. No reports are available on the usefulness of this ratio but the correlation between the ratios in blood and liver tissue might be an indication for usefulness of this ratio for determining vitamin $\mathrm{E}$ status. The ratio of vitamin E:fat percentage in milk we calculated in this study was not correlated to the ratio in blood. This was expected, because milk fat contains a number of components that are formed mainly in the mammary gland from volatile fatty acids (Parodi, 1999), whereas cholesterol determines only a small proportion of milk fat. Liver concentrations of vitamin $\mathrm{E}$ and the ratio of vitamin E:cholesterol show less variation than concentrations in blood. Concentrations of cholesterol in blood change markedly during the periparturient period and are associated with variation in the transport capacity for vitamin $\mathrm{E}$.

Next to this, even with 3,000 IU of vitamin E supplementation, we found a decrease in blood concentrations at calving. In conclusion, we think that liver tissue values of vitamin $\mathrm{E}$ and the ratio of vitamin $\mathrm{E}$ :cholesterol are more representative of vitamin $\mathrm{E}$ status of a cow than blood values.

MDA. In previous research, the oxidative status of dairy cows was evaluated by analyzing several blood concentrations (Brzezinska-Slebodzinska et al., 1994; Bernabucci et al., 2002), but it seems that the oxidative status of a cow should be evaluated using other values. Additionally, it is important to know which samples or combination of samples will provide optimal results. We evaluated liver tissue and milk concentrations as predictors for blood MDA concentrations and found a relationship between blood and milk MDA. This link was identified recently in rats; there is a relation between plasma and tissue oxidative damage, and a correlation between liver and plasma (Koksal et al., 2004). However, no vitamin $\mathrm{E}$ supplementation was involved in these experiments with rats. We found that vitamin $\mathrm{E}$ influences MDA concentrations in liver tissue, but found no correlation between MDA and vitamin E concentrations in blood and milk. This could explain why, in our study, MDA concentrations in liver tissue were not useful as predictors for MDA blood concentrations. As hypothesized before, MDA in blood may merely reflect the total oxidative damage formed in the rest of the body, and MDA in milk may be excreted from blood to the mammary gland. If so, this explains why MDA concentrations in blood and milk are correlated and why liver concentrations show different results.

\section{CONCLUSIONS}

We concluded that periparturient dairy heifers experience oxidative stress, based on increased MDA blood concentrations at calving. Overall, we found that the influence of vitamin $\mathrm{E}$ supplementation on oxidative damage differs in blood, liver, and mammary gland. Vitamin E supplementation reduces oxidative damage in the liver, but has no obvious effect on milk and blood MDA concentrations. We found a strong relationship between blood and liver tissue vitamin $\mathrm{E}$ and the ratio of vitamin E to cholesterol, whereas MDA concentra- 
tions in blood and milk were correlated. In conclusion, blood values of vitamin $\mathrm{E}$ and MDA alone might not be representative for the whole animal.

\section{ACKNOWLEDGMENTS}

This study is part of the 5-yr mastitis program of the Dutch Udder Health Centre and was financially supported by the Dutch Dairy Board. The authors are grateful to Provimi BV (Rotterdam, the Netherlands) for donation of vitamin $\mathrm{E}$. The authors acknowledge $\mathrm{E}$. H. J. M. Jansen, J. A. Stegeman, and T. J. G. M. Lam for critical comments.

\section{REFERENCES}

Arnold, R. N., S. C. Arp, K. K. Scheller, S. N. Williams, and D. M. Schaefer. 1993. Tissue equilibration and subcellular distribution of vitamin E relative to myoglobin and lipid oxidation in displayed beef. J. Anim. Sci. 71:105-118.

Baldi, A., G. Savoini, L. Pinotti, E. Monfardini, F. Cheli, and V. Dell'Orto. 2000. Effects of vitamin E and different energy sources on vitamin E status, milk quality and reproduction in transition cows. J. Vet. Med. A Physiol. Pathol. Clin. Med. 47:599-608.

Bernabucci, U., B. Ronchi, N. Lacetera, and A. Nardone. 2002. Markers of oxidative status in plasma and erythrocytes of transition dairy cows during hot season. J. Dairy Sci. 85:2173-2179.

Bernabucci, U., B. Ronchi, N. Lacetera, and A. Nardone. 2005. Influence of body condition score on relationships between metabolic status and oxidative stress in periparturient dairy cows. J. Dairy Sci. 88:2017-2026.

Brzezinska-Slebodzinska, E., J. K. Miller, J. D. Quigley, III, J. R. Moore, and F. C. Madsen. 1994. Antioxidant status of dairy cows supplemented prepartum with vitamin E and selenium. J. Dairy Sci. 77:3087-3095.

Burton, G. W., and M. G. Traber. 1990. Vitamin E: antioxidant activity, biokinetics, and bioavailability. Annu. Rev. Nutr. 10:357-382.

Castillo, C., J. Hernandez, A. Bravo, M. Lopez-Alonso, V. Pereira, and J. L. Benedito. 2005. Oxidative status during late pregnancy and early lactation in dairy cows. Vet. J. 169:286-292.

Ferre, N., J. Camps, A. Paul, M. Cabre, L. Calleja, J. Osada, and J. Joven. 2001. Effects of high-fat, low-cholesterol diets on hepatic lipid peroxidation and antioxidants in apolipoprotein E-deficient mice. Mol. Cell. Biochem. 218:165-169.

Goff, J. P., and J. R. Stabel. 1990. Decreased plasma retinol, alphatocopherol, and zinc concentration during the periparturient period: effect of milk fever. J. Dairy Sci. 73:3195-3199.

Halliwell, B., and S. Chirico. 1993. Lipid peroxidation: Its mechanism, measurement, and significance. Am. J. Clin. Nutr. 57(5 Suppl):715S-724S.

Herdt, T. H., and J. C. Smith. 1996. Blood-lipid and lactation-stage factors affecting serum vitamin $\mathrm{E}$ concentrations and vitamin $\mathrm{E}$ cholesterol ratios in dairy cattle. J. Vet. Diagn. Invest. 8:228-232.

Hidiroglou, N., G. Butler, and L. R. McDowell. 1990. Plasma and tissue vitamin $\mathrm{E}$ concentrations in sheep after administration of a single intraperitoneal dose of DL-alpha-tocopherol. J. Anim. Sci. 68:782-787.

Jensen, S. K., A. K. Johannsen, and J. E. Hermansen. 1999. Quantitative secretion and maximal secretion capacity of retinol, betacarotene and alpha-tocopherol into cows' milk. J. Dairy Res. 66:511-522.
Koksal, G. M., C. Sayilgan, S. Aydin, H. Oz, and H. Uzun. 2004. Correlation of plasma and tissue oxidative stresses in intra-abdominal sepsis. J. Surg. Res. 122:180-183.

LeBlanc, S. J., T. F. Duffield, K. E. Leslie, K. G. Bateman, J. TenHag, J. S. Walton, and W. H. Johnson. 2002. The effect of prepartum injection of vitamin $\mathrm{E}$ on health in transition dairy cows. J. Dairy Sci. 85:1416-1426.

Lohrke, B., T. Viergutz, F. Becker, K. Gollnitz, A. Hurtienne, and F. J. Schweigert. 2005. Relationship between oxidant stress and milk productivity in dairy cows. Berl. Munch. Tierarztl. Wochenschr. 118:265-269.

Loor, J. J., H. M. Dann, R. E. Everts, R. Oliveira, C. A. Green, N. A. Guretzky, S. L. Rodriguez-Zas, H. A. Lewin, and J. K. Drackley. 2005. Temporal gene expression profiling of liver from periparturient dairy cows reveals complex adaptive mechanisms in hepatic function. Physiol. Genomics 23:217-226.

Mehrzad, J., L. Duchateau, S. Pyorala, and C. Burvenich. 2002. Blood and milk neutrophil chemiluminescence and viability in primiparous and pluriparous dairy cows during late pregnancy, around parturition and early lactation. J. Dairy Sci. 85:3268-3276.

Miller, J. K., E. Brzezinska-Slebodzinska, and F. C. Madsen. 1993. Oxidative stress, antioxidants, and animal function. J. Dairy Sci. 76:2812-2823.

Moyo, N., M. Nielen, C. Kruitwagen, and A. C. Beynen. 2004. Vitamin $\mathrm{E}$ and udder health: A meta-analysis. IDF, Maastricht, the Netherlands.

Naziroglu, M., A. Karaoglu, and A. O. Aksoy. 2004. Selenium and high dose vitamin $\mathrm{E}$ administration protects cisplatin-induced oxidative damage to renal, liver and lens tissues in rats. Toxicology 195:221-230.

Nielsen, F., B. B. Mikkelsen, J. B. Nielsen, H. R. Andersen, and P. Grandjean. 1997. Plasma malondialdehyde as biomarker for oxidative stress: Reference interval and effects of life-style factors. Clin. Chem. 43:1209-1214.

Nockels, C. F., K. G. Odde, and A. M. Craig. 1996. Vitamin E supplementation and stress affect tissue alpha-tocopherol content of beef heifers. J. Anim. Sci. 74:672-677.

O'Boyle, N., C. M. Corl, J. C. Gandy, and L. M. Sordillo. 2006. Relationship of body condition score and oxidant stress to tumor necrosis factor expression in dairy cattle. Vet. Immunol. Immunopathol. 113:297-304.

Ohta, Y., M. Kongo-Nishimura, Y. Imai, T. Matsura, A. Kitagawa, and K. Yamada. 2006. $\alpha$-Tocopherol protects against alpha-naphthylisothiocyanate-induced hepatotoxicity in rats less effectively than melatonin. Chem. Biol. Interact. 161:115-124.

Parodi, P. W. 1999. Conjugated linoleic acid and other anticarcinogenic agents of bovine milk fat. J. Dairy Sci. 82:1339-1349.

Politis, I., I. Bizelis, A. Tsiaras, and A. Baldi. 2004. Effect of vitamin E supplementation on neutrophil function, milk composition and plasmin activity in dairy cows in a commercial herd. J. Dairy Res. 71:273-278.

Smith, K. L., J. S. Hogan, and W. P. Weiss. 1997. Dietary vitamin $\mathrm{E}$ and selenium affect mastitis and milk quality. J. Anim. Sci. 75:1659-1665.

Trevisan, M., R. Browne, M. Ram, P. Muti, J. Freudenheim, A. M. Carosella, and D. Armstrong. 2001. Correlates of markers of oxidative status in the general population. Am. J. Epidemiol. 154:348-356.

van Oostrom, A. J. H. H. M., T. P. Sijmonsma, C. Verseyden, E. H. J. M. Jansen, E. J. P. de Koning, T. J. Rabelink, and M. Castro Cabezas. 2003. Postprandial recruitment of neutrophils may contribute to endothelial dysfunction. J. Lipid Res. 44:576-583.

Weiss, W. P., J. S. Hogan, K. L. Smith, and K. H. Hoblet. 1990a. Relationships among selenium, vitamin $\mathrm{E}$, and mammary gland health in commercial dairy herds. J. Dairy Sci. 73:381-390.

Weiss, W. P., D. A. Todhunter, J. S. Hogan, and K. L. Smith. 1990b. Effect of duration of supplementation of selenium and vitamin $\mathrm{E}$ on periparturient dairy cows. J. Dairy Sci. 73:3187-3194. 